\title{
The Impact of Knowledge Management on Organizational Innovation
}

\author{
Zaneta Simanaviciene ${ }^{1}$, Edmundas Jasinskas ${ }^{2}$, Arturas Simanavicius ${ }^{3}$, Liudmila \\ Shaybakova ${ }^{4, *}$
}

\author{
${ }^{1}$ Mykolas Romeris University, Vilnius, Lithuania \\ ${ }^{2}$ Lithuanian Sport Uuniversity, Vilnius, Lithuania \\ ${ }^{3}$ Lithuanian Sport Uuniversity, Vilnius, Lithuania \\ ${ }^{4}$ Ural State University of Economics, Yekaterinburg, Russia \\ ${ }^{*}$ Corresponding author.Email: econlaw@mail.ru
}

\begin{abstract}
Every organization wants to create unique products and services, but not all organizations achieve this. Those that successfully offer exceptional products and services thanks to better execution processes can be called innovative organizations. However, the desire to be an innovative organization alone is not enough, organizations need to develop new processes in order to be successful and to properly manage the knowledge of the organization. This article analyzes the impact of knowledge management on organizational innovation, and presents the research conducted in Lithuania. Many researchers see a positive impact on organizational innovation, as knowledge management practices that prioritize the generation of new knowledge and learning at the organizational level are important for achieving positive results in innovation. Thus, knowledge generation has a positive correlation with organizational innovation creation, but some researchers, e.g. Donate and de Pablo (2015) consider this relationship to be indirect. The results of a study by Lee, Leon, Hew, and Ooi (2013) revealed that knowledge acquisition is not strongly related to an organization's technology innovation process. Capon, Farley, Lehmann, and Hulbert (1992) argue that the acquisition of knowledge does not affect an organization's ability to innovate. However, there are other studies, e.g. Darroc and McNaughton (2002) and Tan and Nasurdin (2011) argue that knowledge acquisition strongly influences the process of technological innovation. The aim of this article is to determine whether this impact is direct or indirect, not only to limit technological innovations, and to determine which trends are typical for Lithuanian organizations.
\end{abstract}

Keywords: knowledge management, learning organization, innovation management, innovative organization.

\section{INTRODUCTION}

An organization that wants to develop successfully and fulfill its long-term plans must definitely be innovative. Given the rapidly changing modern economic environment, an organization must be able to effectively manage innovations and constantly look for new processes to improve them. Scientific problem how to manage knowledge to increase the innovation of the organization?

More and more researchers are examining knowledge management processes $[1,2,3,4,5]$ and organizational innovation $[6,7,8]$ aspects. There is a positive relationship between an organization's knowledge management and its technological innovation $[9,10,11,12,13,14,15]$, however, some researchers identify a direct link and others - indirect. To better understand the impact of knowledge management on organizational innovation and to investigate whether knowledge management affects more than technological innovation, this article analyzes the impact of knowledge management on innovation based on research on the impact of management on organizational innovation in Lithuania.

The object of the work is the impact of knowledge management on the innovation of the organization. 
The goal is to determine the impact of knowledge management on organizational innovation.

Work tasks:

1. To determine the level of empirical research on the impact of knowledge management on organizational innovation;

2. To reveal the impact of knowledge management on organizational innovation in Lithuania.

Methods: analysis of scientific literature, questionnaire survey, statistical analysis.

\section{THE IMPACT OF KNOWLEDGE MANAGEMENT ON ORGANIZATIONAL INNOVATION IN A THEORETICAL ASPECT}

Knowledge management is defined as a set of activities, initiatives, and strategies that organizations use to generate, transfer, and use knowledge to improve an organization's activities. Research initiatives tend to generate new knowledge, while practical ones seek to manipulate existing knowledge [1,16,].

Knowledge generation is the process of creating new knowledge or supplementing existing knowledge, but when generating new knowledge, organizations may forget about existing knowledge. Knowledge management practices for these reasons should focus on integrating and using existing knowledge to facilitate organizational activities and problem-solving approaches [1].

Effective knowledge management practices are mentioned in the scientific literature as a method for improving organizational innovation. Darroch, J., \& McNaughton, R. [3] conducted a comprehensive study of the scientific literature related to the relationship between knowledge management and innovation and conclude that knowledge management practices are most commonly associated with innovation progress. Other researchers [7] also conclude that the ability to generate new ideas and innovation are directly related. Other research also shows a positive relationship between market knowledge acquisition and innovation $[10,17]$. The findings of these studies suggest that knowledge management practices that prioritize new knowledge generation and learning at the organizational level are fundamental to achieving positive innovation outcomes.

Kazanjian, Drazin, Glynn [2] note that the dissemination and application of knowledge are key factors in the success of new product development. Research shows that socialization skills, both formal and informal, influence the dissemination of knowledge within an organization and improve product development outcomes [18]. Due to their complexity, ambiguity, and uniqueness in the organization, the dissemination and application of knowledge in the scientific literature emerges as key components in creating a long-term, innovation-based, competitive advantage [1]. Thus, the dissemination and application of knowledge has a positive theoretical relationship with the innovation process.

Although research to date considers knowledge storage to be a process of knowledge utilization, [12] consider the relationship between this process and innovation to be indirect. Purvis, Sambamurthy, Zmud [19] identify knowledge management platforms as coded knowledge that facilitates the performance of existing tasks related to the innovation process, thus helping to create new technological processes. Ren, Carley, and Argote [20] found by empirical methods that organizations improve the quality of their products through the interaction of knowledge storage and transfer. It is also important to mention that knowledge management systems are much more effective when an organization has a developed personalized knowledge management strategy.

Knowledge-oriented leadership is an essential element for technology firms looking to innovate. The results of an empirical study by Donate and de Pablo [12] showed that the existence of such leadership is crucial for knowledge management and generation. Knowledge-oriented leadership encourages substantial investment and development progress to generate more knowledge.

Lee, Leon, Hew, and Ooi [10] conducted a study that interviewed top executives (department heads, managers, senior managers, directors) of 162 Malaysian manufacturing companies. The questionnaire was checked by both academics and practitioners before sending it to respondents to ensure clarity and necessity of the questions. $76.5 \%$ of the surveyed organizations had more than 200 employees, 91.4\% applied ISO standards, $84 \%$ were foreign capital companies.

Based on data from previous studies and the scientific literature, [10] put forward the following hypotheses for their research:

1. There is a positive link between knowledge acquisition and technological innovation;

2. There is a positive link between knowledge sharing and technological innovation;

3. There is a positive link between the application of knowledge and technological innovation;

4. There is a positive link between knowledge accumulation and technological innovation;

5. Knowledge acquisition is directly related to knowledge sharing;

6. Knowledge sharing is directly related to the application of knowledge;

7. The acquisition of knowledge is directly related to the application of knowledge. 
19 survey questions were designed to assess the acquisition, application, accumulation and sharing of knowledge.

The results of a study by Lee, Leon, Hew, and Ooi [10] revealed that knowledge acquisition is not strongly related to an organization's technology innovation process. The results of the study did not agree with the tendencies obtained by Darroc and McNaughton [9] and Nasurdin [21] that knowledge acquisition strongly influences the process of technological innovation, but confirmed Capon, Farley, Lehmann, and Hulbert [7] that knowledge acquisition does not affect organizational capabilities. create innovation. This means that an organization's ability to acquire new knowledge, for example, from other organizations, universities, vocational schools, etc., is not important enough for an organization's process of technological innovation.

This statement was supported by Finnish researchers Inkinen, Kianto, Vanhala [11], who in 2013 surveyed 259 Finnish organizations with more than 100 employees (of which $37.8 \%$ were manufacturing companies, $16.2 \%$ trading companies, $9.7 \%$ services) companies, $8.1 \%$ of transport and warehousing companies) concluded that their study did not show a statistically significant link between knowledge management practices and the organizational innovation process. Finnish researchers argue that such results could be explained by Kianto et al's [11] theoretical statement that innovation is an integral result of an organization's knowledge resources and systemic knowledge management practices.

Knowledge sharing, on the other hand, according to a study by Lee, Leon, Hew, and Ooi [10], has a significant positive impact on an organization's technological innovation process. Such results mean that knowledge sharing increases an organization's ability to access the information it needs, which directly affects an organization's technological innovation process. These results were consistent with those of Calantone, Cavusgil, and Zhao [17], but contradicted the findings of Darroc and McNaughton [3] that knowledge diffusion does not have a significant impact on an organization's technological innovation process. When information (best practices used by the organization, employee suggestions, goals of the organization, announcements of the latest innovations in the organization) are easily accessible to all members of the organization, it increases the technological competitiveness of the organization, leading to a better understanding of how to use new techniques. create new products.

The results of the study in Malaysia also showed that the application of knowledge has a strong positive relationship with the organization's technological innovation process. Such results are consistent with the findings of Darroc and McNaughton [3] that responsiveness to available knowledge is an important factor in introducing and improving innovation. This shows that when new knowledge is examined and used to replace old ones, an organization has a greater potential to quickly develop new products using the latest techniques.

Knowledge retention, as research has shown, also has a strong positive relationship with technological innovation. Such a conclusion contradicts the statement of Abbey [22] and Tang [23] that the relationship between organizational memory and innovation is not strong. Thus, an organization's ability to store knowledge can help that organization share knowledge more effectively, thereby enabling employees to find the information they need more quickly, thus enabling a higher level of administrative and technological innovation.

The results of the study also revealed a strong link between knowledge acquisition, sharing and application.The knowledge acquisition also has a strong influence on the application of knowledge, which means that an organization that is more inclined to acquire new knowledge is also more likely to use that knowledge in its business processes.

After a correlation analysis of the questionnaire, Inkinen, Kianto, and Vanhala [11] also concluded that strategic knowledge management has a positive impact on an organization's innovation process. These researchers also note that innovation processes are of better quality in organizations that view knowledge management as a key factor in strategy development and planning and periodically update their strategy with new information.

Inkinen, Kianto, and Vanhala [11] note that the knowledge-based compensation model is also an important factor in fostering organizational innovation. Such human resource management practices encourage employees to participate in knowledge management processes by motivating them through a reward and promotion system that considers the processes of knowledge sharing, acquisition and use. It should also be noted that knowledge-based IT practices can be an important factor in an organization's innovation process.

Such findings were supported by the results of a study by Darroch [3] in New Zealand of organizations with 50 or more employees, in which senior executives were asked to answer questions about knowledge management methodologies in the respondent organization. A total of $443 \mathrm{New}$ Zealand organizations were surveyed, and the results of the study showed that an organization with knowledge management systems is more innovative than an organization without such systems. The fact that organizations with knowledge management systems in place are more likely to develop innovative solutions is most likely due to the fact that such organizations are generally simply better able to use their resources efficiently. 
The knowledge management-based compensation system mentioned by Inkinen, Kianto, and Vanhala [11] can be used, where employees are encouraged to share knowledge with each other and apply it in daily tasks, motivating higher salaries and possible promotions for such techniques.

The interrelationship between the components of knowledge management (acquisition, sharing, application, storage) is also important, as it can help organizations better understand how to manage knowledge in order to have a positive impact on an organization's innovation performance.

It is widely accepted in the scientific literature that knowledge that is intangible is more difficult for competitors to access and less easily plagiarized, and therefore has a greater potential to provide a competitive advantage [4, 24, 25]. A study in New Zealand showed that it is important not only to have the necessary knowledge, but also to be able to dispose of it.

\section{RESEARCH METHODOLOGY AND ORGANIZATION}

The questionnaire method was chosen to gather a large amount of accurate information about organizations, and the questionnaire method has been used in many similar studies on the impact of knowledge management on organizational innovation [ $5,6,8,10,14]$. The questionnaire was based on research conducted by researchers Lee, Leong, Hew, Ooi [10], Massingham [5] Baregheh, Rowley, Sambrook, Davies [6] and 5 points Likert scale. Other questions were designed to collect data on the organizations involved in the study (area of activity of the organization, size by number of employees).

The survey sample was calculated based on the data of the Lithuanian Department of Statistics on Lithuanian enterprises and the research sample Paniott' formula was used. According to the latest data of the Lithuanian Department of Statistics, 76,457 enterprises operated in Lithuania, therefore, applying a 5\% error, a representative sample of the survey is 382 respondents.

\section{RESEARCH RESULTS AND ANALYSIS}

In order to determine the respondents' opinion on the relationship between knowledge management and organizational innovation, the question "Evaluate how you think organizational learning has an impact on these organizational characteristics" was asked, and their relationship to organizational learning, where 5 - strong positive, 4 - positive, 3 - neither positive nor negative, 2 - negative, 1 - strong negative.

The vast majority of respondents $(41.3 \%)$ said that organizational learning has a strong positive effect on responding to market changes. $37.8 \%$ of respondents agreed that such a relationship is positive, $16.7 \%$ cite such an effect as neither positive nor negative, and only $3.3 \%$ consider such a relationship to be negative.

To determine whether organizations not only understand but also apply knowledge management methodologies, a third question of the questionnaire was developed, in which respondents assessed knowledge management criteria. The statements were assessed by the respondents on a five-point Likert scale, where 5Strongly agree, 4 - Agree, 3 - Partially agree, 2 Strongly disagree, 1 - Strongly disagree.

The organizations were further grouped according to the ratings of the statements. Organizations whose average score on the Likert scale was higher than 4.5 were assigned to the very high knowledge management development group (19.3\%), organizations with a mean score on knowledge management statements in the range $(3.5 ; 4.4)$ were assigned to the high knowledge management development group (41.3\%), analogously Likert scale means were in the ranges $(2.5 ; 3.4),(1.5$; $2.4)$, $(1 ; 1.4)$ were assigned to the average ( $24.6 \%)$, organizations with low $(11.9 \%)$ and very low knowledge $(2.9 \%)$ management development. The results of the research revealed that the level of knowledge management in Lithuanian organizations is on average high - this means that organizations try to effectively use the knowledge factor, encourage their employees to improve their qualifications, use their creativity and learn to use new skills to improve organizational efficiency.

To find out whether knowledge management and organizational innovation are related, the fourth question of the questionnaire was designed to assess organizational innovation indicators. Respondents rated the eight statements on a five-point Likert scale, where 5 - Strongly agree, 4 - Agree, 3 - Partially agree, 2 Strongly disagree, 1 - Strongly disagree.

The organizations were further grouped according to the ratings of the statements. Organizations with an average Likert score higher than 4.5 were assigned to the very high innovation group, and organizations with a mean innovation score rating in the range $(3.5 ; 4.4)$ were classified as highly innovative. In the ranges (2.5; $3.4),(1.5 ; 2.4),(1 ; 1.4)$ were assigned to organizations with medium, low, and very low levels of innovation.

$17.7 \%$ of organizations are highly innovative, $36.2 \%$ of organizations are innovative, $27.5 \%$ have a medium level of innovation, $14.6 \%$ are not very innovative, $4.0 \%$ of organizations belong to a low level of innovation. Summarizing the results on the innovativeness of organizations, we can say that the vast majority of the surveyed organizations are innovative and strive to be the best in the market.

To find out whether knowledge management has an impact on an organization's innovation, and if so, 
whether this relationship is strong, the results were cross-tabulated. The results show that organizations with high development of knowledge management are also innovative, and organizations with low application of knowledge management methodologies are not very innovative.

The observed possible correlation was verified by regression analysis, during which the Pearson linear correlation coefficient $\mathrm{R}=0.6678$ was calculated, indicating a moderate positive relationship between the level of knowledge management development and organizational innovation.

Thus, the research of the impact of knowledge management on the innovation of the organization revealed that Lithuanian organizations are interested in knowledge management, apply it in the activities of the organization, implement innovations and seek to be an advantage in the market. Descriptive statistical and regression analysis of the data showed that the impact of knowledge management on organizational innovation is moderately positive and organizations that apply knowledge management methodologies are more innovative than those that do not apply knowledge management methodologies.

The trends obtained in this study show that the impact of knowledge management in Lithuanian organizations is of medium strength, therefore it can be stated that this impact depends on the achieved level of market development, therefore different organizations may have different effects, such as Donate and de Pablo and others [7, 10, 12] and Nasurdin [21] found a strong necessary link to technological innovation. The results of this study also complement previous studies, as not only manufacturing companies in Lithuania have been studied and it has been established that knowledge management has a direct positive impact on the organisation's innovation in all sectors of activity and not only on technological innovations.

For these reasons, all organizations that seek to be innovative are encouraged to actively engage in knowledge management activities. Knowledge management activities that are important for the organisation's innovation are that organizations seeking to be innovative should ensure constant communication with industry professionals, encourage employees to develop their competencies, motivate members to share professional knowledge and work experience, exploit employee creativity and allow them to be exposed in the workplace.

These aspects can be implemented through the knowledge management-based employee motivation system mentioned by Inkinen, Kianto and Vanhala [11], which encourages members to share knowledge and apply it in daily tasks, motivating higher salaries and possible promotions for such techniques, or other knowledge management methodologies.
It should be noted that innovative organizations are those that make efficient use of all their available resources, and knowledge is also an asset of an organization, so to increase an organization's innovation, knowledge must be created, accumulated, transferred, stored, and used wisely.

\section{CONCLUSIONS}

1. Knowledge is one of the most important components of an organization's intangible assets. Knowledge management is an organizational philosophy that dictates where, how and when to accumulate, update and explain new knowledge. This philosophy allows an organization to make the best use of its most important resource, the knowledge of its employees. Innovation is generally understood as the application of a new idea in order to qualitatively update a certain model - production technology, product, service, marketing action or human function. Innovation involves generating a new solution to a particular problem and adapting it to make more efficient use of available resources and increase an organization's competitive advantage.

2. Summarizing the study of the scientific literature on the impact of knowledge management on organizational innovation, we can state that such a relationship is theoretically justified. The scientific literature suggests that the ability to manage, share, and adapt information within an organization should have a significant positive impact on an organization's innovation. Empirical research on knowledge management and innovation in an organization has revealed that the theoretically formed impact of knowledge management on organizational innovation is positive and quite pronounced. Based on the research of foreign scientists, it is concluded that by managing knowledge as an organization's resource, paying sufficient attention to it and encouraging members to acquire, deepen, apply, accumulate and accumulate knowledge, positive results can be achieved in the organization's technological innovation process.

3. After performing the impact of knowledge management on the innovation of the organization, it was established that Lithuanian organizations are interested in knowledge management, apply it in the activities of the organization, implement innovations and strive to be innovative in the market. Descriptive statistical and regression analysis of the data showed that the impact of knowledge management on organizational innovation is a direct moderate positive and organizations that apply knowledge management methodologies are more innovative than those that do not apply knowledge management methodologies. 


\section{REFERENCES}

[1] R. M. Grant, Toward a knowledge-based theory of the firm. Strategic management journal, 17(S2), (1996) pp. 109-122.

[2] R. K. Kazanjian, R. Drazin, M. A. Glynn, Creativity and technological learning: the roles of organization architecture and crisis in large-scale projects. Journal of Engineering and Technology Management, 17(3) (2000) pp. 273-298.

[3] J. Darroch, Knowledge management, innovation and firm performance. Journal of knowledge management, 9(3) (2005) pp. 101-115.

[4] N. J. Foss, The emerging knowledge governance approach: Challenges and characteristics. Organization, 14(1) (2007) pp. 29-52.

[5] P. Massingham, An evaluation of knowledge management tools: Part 1-managing knowledge resources. Journal of Knowledge Management, 18(6) (2014) pp. 1075-1100

[6] A. Baregheh, J. Rowley, S. Sambrook, D. Davies, Innovation in food sector SMEs. Journal of Small Business and Enterprise Development, 19(2) (2012) pp. 300-321

[7] N. Capon, J. U. Farley, D. R., Lehmann, J. M. Hulbert, Profiles of product innovators among large US manufacturers. Management Science, 38(2) (1992) pp. 157-169.

[8] C. C. Cheng, J. S. Chen, Breakthrough innovation: the roles of dynamic innovation capabilities and open innovation activities. Journal of Business \& Industrial Marketing, 28(5) (2013) pp. 444-454.

[9] J. Darroch, R. McNaughton, Developing a measure of knowledge. Organizational Intelligence: The Cutting Edge of Intellectual Capital and Knowledge Management, Butterworth-Heinemann/KMCI Press, Boston. 2001, pp. 226-242.

[10] V. H. Lee, L. Y. Leong, T. S. Hew, K. B. Ooi, Knowledge management: a key determinant in advancing technological innovation?. Journal of Knowledge Management, 17(6) (2013) pp. 848-872.

[11] H. T. Inkinen, A. Kianto, M. Vanhala, Knowledge management practices and innovation performance in Finland. Baltic Journal of Management, 10(4) (2015) pp. 432-455.

[12] M. J. Donate, J. D. S. de Pablo, The role of knowledge-oriented leadership in knowledge management practices and innovation. Journal of Business Research, 68(2) (2015) pp. 360-370.
[13] D. Doloreux, R. Shearmur, R. Guillaume, Collaboration, Transferable and Non-transferable Knowledge, and Innovation: A Study of a Cool Climate Wine Industry (Canada). Growth and Change, 46(1) (2015) pp. 16-37.

[14] L. Lebel, P. Garden, A. Luers, D. Manuel-Navarrete, D. H. Giap, Knowledge and innovation relationships in the shrimp industry in Thailand and Mexico. Proceedings of the National Academy of Sciences, 113(17) (2016) pp. 4585-4590.

[15] A. S. Cui, F. Wu, Utilizing customer knowledge in innovation: antecedents and impact of customer involvement on new product performance. Journal of the Academy of Marketing Science, 44(4) (2016) pp. 516-538.

[16] J. G. March, Exploration and exploitation in organizational learning. Organization science, 2(1) (1991) pp. 71-87.

[17] R. J. Calantone, S. T. Cavusgil, Y. Zhao, Learning orientation, firm innovation capability, and firm performance. Industrial marketing management, 31(6) (2002) pp. 515-524.

[18] B. Lawson, K. J. Petersen, P. D. Cousins, R. B. Handfield, Knowledge sharing in interorganizational product development teams: The effect of formal and informal socialization mechanisms. Journal of Product Innovation Management, 26(2) (2009) pp. 156-172.

[19] R. L. Purvis, V. Sambamurthy, R. W. Zmud, The assimilation of knowledge platforms in organizations: An empirical investigation. Organization science, 12(2) (2001) pp. 117-135.

[20] Y. Ren, K. M. Carley, L. Argote, The contingent effects of transactive memory: When is it more beneficial to know what others know? Management Science, 52(5) (2006) pp. 671-682.

[21] C. L. Tan, A. M. Nasurdin, Human resource management practices and organizational innovation: assessing the mediating role of knowledge management effectiveness. Electronic Journal of Knowledge Management, 9(2) (2011) pp. 155-167.

[22] A. Abbey, R\&D work climate and innovation in semiconductors, Academy of Management Journal, 26(2) (1983) pp. 362-8.

[23] H. K. Tang, An inventory of organizational innovativeness, Technovation, 19 (1993) pp. 41-51.

[24] B. Kogut, U. Zander, Knowledge of the firm, combinative capabilities, and the replication of 
technology. Organization science, 3(3) (1992) pp. 383-397.

[25] I. Nonaka, H. Takeuchi, The knowledge creation company: how Japanese companies create the dynamics of innovation. New York: Oxford University Press, 1995. 